the Morton wave-current these vigorous contractions alternate with periods of complete relaxation, and thus by a form of automuscular massage the stasis and congestion of recent sprains are removed, and the return of mobility and function is often hastened by several days or weeks. In the same manner, with suitable technique, the re-absorption of the fluid in synovitis of the knee-joint can be rapidly promoted. A full understanding of the modus operandi of this modality is necessary to enable us to appreciate in what a large number of cases, resulting from wounds and exposure, it is applicable. There is no form of electrical or other apparatus by the use of which quicker or more permanent results can be obtained. I hope that we shall presently hear Captain Humphris's remarks on this treatment, for on account of his much longer experience he is able to speak with far more authority on these matters than I am.

I have so recently read a paper on the ultra-violet radiation before this section that I do not propose to detain you with any remarks of mine on this subject, but we shall be very pleased to hear the experience of others with this treatment.

To summarise very briefly, the war services which electrotherapy can render to the State are as follows:-

1. A consi lerable number of those who would otherwise remain permanently unfit can be rendered fit for general military service.

2. The severe pain of many of those wounded or injured by exposure on military service can be completely arrested or greatly relieved by these methods.

3. Hlectrical treatment is of great service in many of the less serious cases, of ten effecting a speed cure and a quicker return to the figbting line.

4. Electrotherapy, fully and efficiently developed, will result in a very considerable reduction in the amount paid for Srate pensions, and, what is far more important, will restore function to many crippled limbs.

The last point we have to consider is the personnel of the staff of the electrical department, and this, though perhaps the most important point of all, I must deal with very briefly. A great deal of the electrical treatment administered at miny of the convalescent homes and smaller hospitals serves no other purpose than to bring the treatment into disrepute. One frequently sees, as I saw to-day, a patient with complete reaction of degeneration of the musculospiral nerve who har been treated in a perfunctory manner for five weeks with the faradic brush, with no other result, of course, than to destroy completely the patient's faith in all electrical methods. Under the present system with $a b$ out two months' training and the possession of a small faradic battery anyone can become a so-called medical electrician, and practise as an expert the most specialised of all the medical soiences. I think that this condition of things could be largely remedied by appointing properly qualified electrotherapists to supervise and instruct in electrical methods in the different hospitals and convalescent homes in their area. $O E$ course, the more important treatments, sush as diathermy and the static, would have to be conducted at properly organised anil equipped departments. But, nevertheless, under proper supervision and control an amount of work invaluable to the patients and the State conld be performed in the auxiliary hospitals by means of ionisztion and rhpthmically reversed galvanism.

These suggestions are marle in no carping spirit, but with a full recognition of the very valuzble services which are being rendered by only partially trained nurses and masseuses, and they are made with an earnest desire to increase the usefulness of these ladies and to extend the benefits of efficient elentrotherapy to regions which they have not yet reached. This section cannot fail to feel otherwise than much gratified at the development which has occurred in electrotherapy during this war and at the increased recognition which it is daily receiving.

DONATIONS AND BEQUESTS.-Among other bequests the lare Mr. Peter Brock, of Treesbank. Cimbuslany, has left $£ 1500$ to the Western Infirmary and $£ 1250$ to the Royal Infirmary, Glasgow.-The late Edward George Henry Montagu, eighth Earl of Sandwich, has left $£ 1000$ each to the Huntingdon County Hospital, the Dorset County Hospital, and the Royal Hospital for Incurables, Putney.

\section{FRAUD AND SKIN ERUPTIONS.}

By Sir JOHN COLLIE, M.D. Aberd.,

PHYSICIAN, COUNTY OF LONDON WAR HOSPITAL, EPSOM.

LESIONS of the skin may be produced in many ways; even simple rubbing with a wet finger, if persistently carried out, will raise an erythema. This, however, is a somewhat tedious method, and it is sometimes found that friction with the moistened end of a match or persistent pricking with a needle is resorted to, since these plans are quicker and more efficacious. Other methods are the application to the skin of a too hot water-bottle, of carbolic acid (frequently employed since it is very easily obtained), or of agents such as cantharides, mustard, " mustard leaf," or croton oil, all of which blister and may even produce superficial ulceration of the skin. More serious injuries, deep ulceration and gangrene, which are sometimes found, are generally produced by the application of strongly caustic acids or alkalies. One feature of these skin eruptions is that often a succession of diseased areas arise.

Dr. MeKendrick, of Edinburgh, has kindly sent me a note of the following case.

A girl who had undoubted syphilis and a secondary eruption was about to be discharged from the Fidinburgh Royal Infirmary when a fresh crop of eruptions suddenly appeared which was not characteristic of the disease. It subsequently transpired that some of the areas were produced by pinching the skin with the finger-nails, some by rubbing and scratching, and others by the application of heat. The hands were tied up and the whole rash disappeared.

Seven years later the same girl was brought to the surgical $X$ ray department of the same infirmary by the matron of a home for destitute girls, with a report that the girl had swallowed a large number of ordinary pins. $X$ ray examination was negative, and Dr. McKendrick, who fortunately, remembered the girl's face, and said so, obtained from her the confession that she had not in fact swallowed any pins.

The case betokens a peculiarly twisted mental attitude and a moral obliquity which is interesting.

Nature of the lesions. - These lesions appear suddenly and at irregular intervals; they may be single or multiple. There may be a simple erythema, bullæ, or shallow ulcers in rare cases severe, deeply-cut ulcers are found, or even patches of superficial gangrene. They have the following characteristics :-

1. The condition produced is unlike any of the usual skin diseases.

2. According to the usual geography of factitious skin eruptions they occur in situations easily reached by the right hand of the patient, if she is right-handed, or on the opposite side if she is left-banded. Such situations, for example, as the front of the arm and the forearm, and the thigh and the leg are favourite sites. The area between the shoulder blades cannot easily be reached and this is generally found to escape.

3. They avoid the neighbourhood of the mouth, nose, ear, scalp, knees, hands, and the genital region. The soles of the feet are also avoided, as an eruption there would impede locomotion.

4. The lesions often have a characteristic aspect. Usually they run longitudinally - that is to say, in the length of the limb on which they are inflicted. The shape may be curious and suggestive. Ulcers, for example, may be perfectly circular, and in such cases have been produced, in the case of crude imitators, by the application of a coin soaked in some irritant; or, more rarely, they may take the shape of parallel scratches such as might be produced by a fork.

Eruptions following a straight line are unknown in dermatology. Any patch of dermatitis, therefore, which follows a straight line for any part of its margin is suggestive of fraud. A suppurating, angry dermatitis in a more or less straight line may be produced on the outer edge of the left forearm by the simple process of persistent friction by the right hand. It is well to remember that one is apt to be thrown off one's guard by a very inflamed angry-looking patch of inflammation; instinctively, from preconceived ideas and association, the appearance makes one think of disease. Many cases have been recorded where blistering has been produced by the simple process of cutting off a small piece 
of a mustard-plaster and applying it to the skin. The straight lines tell their own tale.

5. The surrounding skin is significantly healthy.

6 . The alleged sensation of the part is usually abnormal ; either the patient complains loudly of excessive pain, even when touched lightly, or else she professes to feel no pain when the part is freely handled.

7. The lesions sometimes have a way of appearing to order. If, for example, the examiner says in the hearing of the patient: "I should not be surprised if in the course of a few days we find an ulcer in such-and-such a place," the probabilities are that later an ulcer in due course appears there. Cases have been described where lesions starting at the periphery of a limb and subjected to the control of an occlusive dressing, such as a plaster-of-Paris case, have appeared higher and higher up the limb as the occlusive dressing has been extended.

8. Much assistance can often be gained by smelling the eruption. The characteristic smell of many acids can be recognised, and the case diagnosed at once. Litmus paper will often reveal an acidity which will at once arouse suspicion, for the normal exudation of a skin disease is alkaline.

In cases which are caused by hysteria other signs, such as stocking anæsthesia, and so forth, can usually be elicited, and an important point to be remembered in all such cases is that they are usually associated with anæsthesia of the palate.

Aids to diagnosis. - The diagnosis will be assisted by a consideration of all of the above points. It should be remembered that occasionally where a strong caustic has been used a drop may run down the skin and leave a pear-shaped mark below the edge of the ulcer, which is lighter in colour and shows a less intense inflammation than the primary lesion. The application of a proper occlusive dressing will often be found useful and will clear up any doubt that remains.

Dr. Edward Stainer, of the Skin Department of St. Thomas's Hospital, has kindly supplied me with a drawing the exact size of what he calls the "tell-tale trickle tail" which occurred in the left arm of a young housemaid, and was obviously produced by an acid. The central circular area was in a blistering condition with detached epithelium, surrounded with an irregular, erythematous border, the

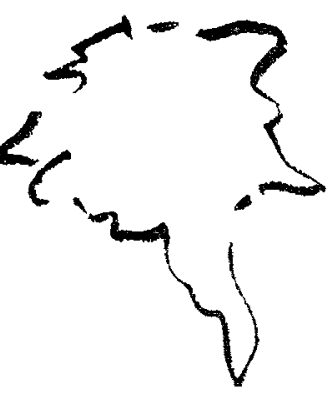

tail of a comma, as it were, representing the overflow of the acid.

Speaking generally, the flattened, sliding epithelium of a large blister in which there are no true pemphigus.like blebs, ought to make one suspect the possibility of artificial production.

Skin lesions, whether genuine or artificial, are often masked by a secondary dermatitis, which may be set up by scratching and the ingress of pyogenic organisms ; these should be got rid of by the application of compresses and other suitable remedies. The character of the lesion depends not only upon the chemical employed to produce it, but upon the mode of its application ; for instance, carbolic solution in certain strengths is an irritant, pure carbolic is an anæesthetic; an application of the former will, therefore, produce a dermatitis, the latter will whiten the tissues, and if the application is sufficiently strong will produce gangrene.

Many years ago, when I was in general practice, I was attending a patient for rheumatic fever. She complained bitterly of two painful spots in each buttock. Two small patches of whitened skin presented themselves, and I at once said, "These are burns with pure carbolic acid." The answer to the question whether a bed-pan was being used was in the affirmative. The trained nurse who was in attendance admitted, upon my putting it to her, that she was in the habit of disinfecting the bed-pan with carbolic solution. The fact that some pure carbolic had been unintentionally left on the utensil was perfectly obvious, but was denied. My patient, however, a woman of much intelligence, required no explanation. The nurse, who had had her lesson, was forgiven, and there the matter ended.

It is often very difficult to discover the means adopted to produce the artificial lesions, for obviously the patient makes it his business to conceal in every possible way the fraud which he knows he has perpetrated. A curious case occurred recently in which circumscribed area of the skin in the forearm presented a suppurating pustular eruption upon an indurated base. The patient was a nurse in a hospital. The case presented many unusual signs, but the true nature of it was soon revealed (as it is in most cases when under hospital supervision) by the fact being disclosed that the nurse was a morphomaniac. She had inserted the hypodermic needle repeatedly within a small area, with the result described.

A somewhat rare but very interesting form of skin disease produced by artificial means is sometimes brought about by striking the skin vigorously with a hard brush, which produces a purpuric rash which has been called "hairbrush purpura."

There are physiological and psychological reasons which will suggest themselves to medical men why reasonable sane girls are found wilfully to produce troublesome, irritating diseases; but here we are more concerned with the class of case in which pecuniary advantage is likely to be gained. Sequeira states that the payment of $£ 5$ to a servant employed in a large institution as compensation for dermatitis, alleged to be caused by irritant soap and alkalies, led to a crop of similar cases coming under his notice.

As a rule, an artificially produced skin lesion can be fairly easily diagnosed; but, as Dr. Norman Walker reminds us, it is one thing to diagnose a dermatitis artefacta and another thing to prove it. In his "Diseases of the Skin" Sequeira gives the following note about the case of a young girl where the lesions were obviously self-inflicted :-

"The illustrative photograph shows the leg of a young girl in whom the lesions were remarkable for their arrangement in sets of three, all of the same length and equidistant. They consisted of rather deep longitudinal abrasions covered with dried blood and small crusts formed by dried exudation. Recent lesions and the stains of older abrasions are well shown in the photograph. The patient had complete anæsthesia of the palate and right hemianæsthesia affecting the face, limbs, and trunk with the exception of a spot the size of a shilling over the right eyebrow, where sensation was normal. It was suggested that the excoriations were produced by a three-pronged fork, but scratching by the finger-nails might have caused them."

Dr. R. O. Adamson, of Glasgow, reports the following interesting case.

The patient was a young lady of more than usually attractive appearance in whom he detected notning suggestive of the morbid tendencies which she exhibited. The illness began with "weeping eczema" of the chin, which was followed by a similar condition on cheeks, forehead, nose, neck, arms, and later the thighs and legs. The condition remained in spite of incessant treatment, and often appeared in places covered by dressings and bandages. Each patch was at first an acute erythematous flush which rapidly suppurated and healed by the usual crust. Their shapes were various, sometimes round, often square, and not infrequently linear. They healed rapidly, but the feature of the illness was the succession of diseased areas. The condition made the young lady a prisoner in the house for many months, and this was borne with remarkable patience. Dr. Adamson remarks: "I confess the idea of the complaint being factitious never occurred to me. Those who have met with such cases for the first time may understand $m y$ want of imagination. I was supported in my sympathy for my patient by a skin specialist who diagnosed dermatitis herpetiformis."

In due course the lady went to a well-known spa and was treated by two or three doctors with no benefit. Eventually the case was diagnosed by a well-known dermatologist as dermatitis artefacta. A nurse was now sent in to watch the patient, but as after two months nothing was detected, fresh patches appearing, the friends of the patient were, with some difficulty, induced to send the lady to a nursing home where she was never left alone night or day, and was never allowed to leave the room for any purpose. On the fourth day a movement under the bedclothes led to the detection of the lady's hand holding most unsuspicionsly a handkerchief in which was a small ragged piece of pumice. stone. When deprived of this her cure was rapid.

Two years later the lady complained of much gastric pain and vomiting of blood. There was plenty of blood, but it clearly had never been in the stomach, for it lay as a pinkish layer at the bottom of a vessel of vomited milk. Notwithstanding her attitude was one of apparent bona fides, after

a few days' careful watching she was informed that her illness was a feigned one, and so the matter ended. 
A year later obstruction of the bowels was feigned, and constipation lasting a month was a verred, the falsity of which was proved by another short sojourn in a nursing home.

Unfortunately, however, we often have to deal with the following much more dificult condition. Pre-existing skin disease is sometimes wilfully aggravated and kept up by patients who derive a monetary benefio from continuing disability. It is an easy matter, for instance, for one whose hands have become inflamed as the result of using at his work too strong a soap or too strong a solution of soda to keep up the eruption by the occasional surreptitious application of the irritants which have in the first place produced it. How often does one see an old ulcer kept going $w h+n$, if properly treated, it should have healed. The only way to deal with such cases is either to apply an occlusive dressing, when this is possible, or to arrange for the patient to be under proper medical supervision in an institution.

Trade dermatitis. - In certain trades where irritants have to be habitually used dermatitis frequently occurs. The most familiar examples are the erytbematous, raw-looking haads of those wh, habitually hive to use strong alkaline solutions - for example, washerwomen, barmaids, \&c. Hairdressers who use alkaline shampooing fluids sometimes suffer. Those who use aniline dyes, french polishers who use bichromate of potassium, grocers who have to handle sugar, carpenters working with teak and rosewood, tanners using arsenic, surgeons and nurses using disinfectants, painters using lead, masons working with silicate, photographers, and workers with chlorine, tar, and paraffin are also liable to disease. Bikers are subject to a special form of eczema, the result of constantly mixing dough. This used to be called "baker's itch," which was probably a form of scabies, the result of the introduction of an acarus from an inferior sort of suyar with which flour used to be adulterated. A worker may have been engaged for years in a particular occupation without his skin suffering, but from some indefinite condition, such for instance as a lowered vitality, or it may be the accidental use of a stronger solution than usual, the skin resistance gives way, and a dermatitis is set up. Even when the condition has thoroughly healed there is sometimes a tendency to recur in the event of a continuous exposure.

The characteristics of the lesions produced are that they only appear in the portions of the body exposed to the action of the ctustic, and are, therefore, almost entirely confined to the hands and forearms. This is not. however, an absolute rule, for if the worker is engaged with caustics in the form of a fine powder or a vapnur, other parts of the body, more especially the axilla and groins, may be afferted. It must be remembered that the clothing may become soaked in the irritant, and unexpected parts of the body may become affected. For instance, a case of acute eczema was recentl $\nabla$ found on both legs in a man whose occupation was that of cleaning down motor-cars; he used a crude form of paraffin, and his trousers hat become soaked with it.

The various trades are responsible for an infinite variety of skin lesions. As a rule, they start with a simple erythema, followed by vesiculation, and eventually an eczematous condition is set up. When the process is chronic, we get the heaping-up of epithelium with formation of hard, horny skin, in which painful cracks are likely to occur. The backs of the hand. the tips and sides of the fingers, and the nails are usually first affected, the disease spreading up the arms as far as the irritant is able to obtain access. The difficulty of many of these cases is that they are so frequently masked by the secondary infection caused by scratching and the ingress of progenic organisms. In a suspicious case p irticular attention should be paid to the ends of the fingers and the finger-nails; and microscopic examination of the epithelium will often repay the searcher

Dermatitis from plants - Manp plants, either from the presence of irritating hairs or from their secreting an irritating oil, have the power of producing dermatitis in people who handle them. The most familiar example of this is the common stinging-nettle, but the primula farilv, especially Primulx obomica, is particularly prone to do this. as also are $R$ hus toxieodentron, Rhus venenata, Rhus divertiloha, and Lxportea gigas. Certain bulbs. alsn, such as the scilla produce an artificial dermatitis. Primuln ohnnien is a poisonous plant which closely resembles the Engliah primrose ; its leaf contains a number of spines which rearlily attach themselves to the skin and set up an acute inflammation. Many people, however, seem to have an immunity from the poisonous effects. Laportea gigas (a tropical stinging-nettle) has a fruit like a raspberry, and the small hairs on the stems and leaves seem to have the power of setting up a dermatitis. The eruption produced by these plants, as a rule, starts on the lateral surfaces of the fingers and spreads to the back of the hand, involving the front and back of the wrist and front and back of the forearm. It closely resembles erysipelas, for which disease it is often mistaken. The eruption consists, as a rule, of an erythema covered with closely packed vesicles and a considerable amount of subcutaneous swelling. It generally lasts from a few days to two, three, or four weeks.

Porchester-terrace, W.

\section{A CASE OF}

\section{MENINGOCOCCAL INFECTION WITHOUT INVOLVEMENT OF THE CEREBRO- SPINAL SYSTEM.}

By W. M. elltotT, M.B., Сh.B. Glasg., D.P.H. Camb. ACTING PHYSICIAN-SUPERINTENDENT, CITY OF GLASGOW FEVEB

$$
\text { hospital, RUChLLL. }
$$

THE following account of a case coming under my care may prove of interest in view of the fact that reports of instances of meningococcal infection other than meningeal are so far scarce.

A private in the Royal Field Artillery, aged 19, was admitted to hospital on March 11th, 1915, with the history of having four days before (following a period of some days during which he bad been suffering from a "cold") become ill suddenly with shivering, headache, and generalised pains in the back and limbs, and a feeling of feverishness. He took to his bed, and in the course of a day or two a rash began to come out on the body. The acute symptoms per sisted and were accompanied by an elevated temperature. A provisional diagnosis of typhus fever was made and his removal to hospital was ordered. His condition on admission was as follows: Temperature $104^{\circ} \mathrm{F}$. pulse 120 , respirations 24 . The patient appeared acutely ill and com plained of pain all over the body. His expression was quite intelligent, though his eyes were somewhat heavy and suffused and there was slight conjunctival discharge. and he was able to give perfectly coherent answers to questions regarding his illness. A rash was present which consisted of three elements-erythematous blotches petechial spots, and very shallow vesicles which contained blood. The erythematous spots were distributed over the trunk and limbs in a manner similar to measles, but they were not raised above the level of the skin. The petechial spots were confined to the arms and legs, and occurred as minute purplish spots scattered through the erythema and showed a distinct tendency to be collected into small groups. The vesicular elements were entirely confined to the legs and were few in number, though some were as large as a sixpence; they were formed by the lifting of the superficial layers of the epidermis by the effusion of a thin layer of blood; in every case they had become dry, and on breaking through the surface dried blood could be scraped out from underneath. The pulse was rapid and bounding, but of good quality and regular. The cardiac sounds and dullness were normal. The pulmonary area was everywhere resonant, and no alteration in the breath sounds was to be heard, nor were any adventitious sounds present. The tongue was lightly coated and the throat slightly reddened. Examination of the abdomen revealed no abnormality. The stools were normal, though there was a tendency to constipation. The patient's mental condition appeared quite normal. The tendon reflexes showed no abnormality and there was no post-cervical stiffness and no Rernig's sign. 'The urine contained a haze of albumin, but no blood or tube casts. The diagnosis of typhus fever was discarded owing to the clearness of the patient's mental condition and the fact that, though the rash simulated the trphus exanthem fairly closely, there were distinct points of difference.

The subsequent course of the case was as follows:March 12th: Temperature $104^{\circ}-101^{\circ}$ (falling). The rash was still bright; the general pain persisted; the mental condition remained quite clear. Lumbar puncture was performed and a clear fluid obtained, which was not ander undue pressure and which remained free from clot, and was found microscopically to contain only normal cells. 13th : Temperature: morning 99.2 $2^{\circ}$, evening $99 \cdot 6^{\circ}$. Rash beginning to fade on the trunk but still bright on the arms and legs. Pains less severe. 14th: Temperature: morning $98.8^{\circ}$, evening $98 \cdot 6^{\circ}$. Rash faded on trunk but still present on 